\title{
Significant decrease of saturation index in erythrocytes membrane from subjects with non-alcoholic fatty liver disease (NAFLD)
}

\author{
Maria Notarnicola ${ }^{1,2^{*}}$, Maria Gabriella Caruso', Valeria Tutino ${ }^{1}$, Caterina Bonfiglio ${ }^{1}$, Raffaele Cozzolongo1, \\ Vito Giannuzzi ${ }^{1}$, Valentina De Nunzio', Giampiero De Leonardis', Daniela I. Abbrescia', Isabella Franco', \\ Vincenza Intini ${ }^{1}$, Antonella Mirizzi ${ }^{1}$ and Alberto R. Osella ${ }^{1}$
}

\begin{abstract}
Background: The lipidomic profiling of erythrocyte membranes is expected to provide a peculiar scenario at molecular level of metabolic and nutritional pathways which may influence the lipid balance and the adaptation and homeostasis of the organism. Considering that lipid accumulation in the cell is important in promoting tissue inflammation, the purpose of this study is to analyze the fatty acid profile in red blood cell membranes of patients with Non-Alcoholic Fatty Liver Disease (NAFLD), in order to identify and validate membrane profiles possibly associated with the degree of hepatic damage.

Methods: This work presents data obtained at baseline from 101 subjects that participated to a nutritional trial (registration number: NCT02347696) enrolling consecutive subjects with NAFLD. Diagnosis of liver steatosis was performed by using vibration-controlled elastography implemented on FibroScan. Fatty acids, extracted from phospholipids of erythrocyte membranes, were quantified by gas chromatography method.

Results: The subjects with severe NAFLD showed a significant decrease of the ratio of stearic acid to oleic acid (saturation index, SI) compared to controls, $1.281 \pm 0.31$ vs $1.5 \pm 0.29$, respectively. Low levels of SI in red blood cell membranes, inversely associated with degree of liver damage, suggest that an impairment of circulating cell membrane structure can reflect modifications that take place in the liver. Subjects with severe NAFLDalso showed higher levels of elongase 5 enzymatic activity, evaluated as vaccenic acid to palmitoleic acid ratio.
\end{abstract}

Conclusions: Starting from these evidences, our findings show the importance of lipidomic approach in the diagnosis and the staging of NAFLD.

Keywords: Lipidomic analysis, Fatty acids profile, NAFLD, Erythrocyte membrane, Saturation index

\section{Background}

The maintenance of physiological cell membrane fluidity is a prerequisite associated with normal cell growth and division [1] and its alterations have been described in various pathologies, such as obesity, diabetes mellitus and different types of cancer [1-4]. Lipid accumulation in the cell is important in promoting tissue inflammation [5] and

\footnotetext{
* Correspondence: maria.notarnicola@irccsdebellis.it

${ }^{1}$ National Institute of Gastroenterology "S. de Bellis" Research Hospital, 70013 Castellana Grotte, Bari, Italy

${ }^{2}$ Laboratory of Nutritional Biochemistry, National Institute of

Gastroenterology "S. de Bellis", Research Hospital, Castellana Grotte, Bari, Italy
}

this damage is not caused not only by the quantity but also by the quality of accumulated lipids in the cells [6]. In this contest, lipidomic analysis, as a new technology, allows to identify specific metabolic profiles, typical of a disease, as NAFLD.

The lipidomic profiling of erythrocyte membranes provides exhaustive information on metabolic and nutritional pathways which influence the lipid balance and homeostasis of the organism. Several studies have demonstrated that the analysis of fatty acids composition of circulating erythrocyte membrane can be considered an appropriate biomarker for investigating the relations 
between the patterns of fatty acid metabolism and specific diseases [7, 8], considering that changes in fatty acids composition of erythrocyte membranes may be related to illness status.

Previously, we showed the presence of an altered fatty acid profile in erythrocyte membranes of patients with colorectal cancer [9]. The patients suffered of colorectal cancer showed a lower percentage of total $n$-3-series polyunsaturated fatty acids (n-3-PUFAs) than controls and consequently this finding was reflected in the higher ratio $\mathrm{n}$-6-PUFA/n-3-PUFA observed in patients having cancer compared to controls.

The saturation index (SI) of cell membrane is the ratio of stearic acid to oleic acid and it is considered an indicator of membrane rigidity [7]. Low levels of SI have been associated to the cell malignant phenotype [3]. Analysis of fatty acid extracted from leukemic cells and solid tumor tissue showed a significant increase in the oleic acid content respect to stearic acid [10, 11].In erythrocytes membranes, low levels of SI have been demonstrated to be predictors of postmenopausal breast cancer [12].

A lipidomic approach has been considered for the detection of the major lipid classes and for the distribution of fatty acids in cell membrane in experimental models of NAFLD and Non-alcoholic Steato-Hepatitis (NASH) $[5,13]$. A modified lipidomic profile has been observed in NAFLD, suggesting that changes in the concentration and quality of lipids in cell membranes might affect the pathogenesis and progression of steatosis or steatohepatitis. Furthermore, NAFLD has been associated with an increase in saturated fatty acids altering the hepatic lipid profile in patients with liver damage [5, 6].

Therefore, considering that the changes in the concentration and quality of fatty acids play a central role in the development and progression of NAFLD, the present study was designed to analyze the fatty acids profile in red blood cell membranes of patients with NAFLD in order to identify and validate membrane profiles associated with hepatic injury. Moreover, a possible clinical association between specific lipidomic profiles and degree of liver damage will be assessed.

\section{Methods \\ Patients}

This work is part of NUTRIATT (NUTRItion and AcTiviTy) study, a nutritional trial (registration number: NCT02347696) enrolling consecutive subjects with NAFLD. Diagnosis of NAFLD was performed by using vibration-controlled elastography (VCTE) implemented on FibroScan ${ }^{\circ}$ (Echosens, Paris, France.) [14]. NAFLD was categorized as absent $(<215 \mathrm{~dB})$, mild $(215-250 \mathrm{~dB})$, moderate $(251-299 \mathrm{~dB})$ and severe $(\geq 300 \mathrm{~dB})$ [15].
Trial inclusion criteria included: Body Mass Index (BMI) $\geq 25$, calculated as weight in kilograms divided by the square of the height in meters $\left(\mathrm{kg} / \mathrm{m}^{2}\right)$; age $>30$ years old and $<60$ years old; NAFLD moderate or severe. Exclusion criteria included: overt cardiovascular disease and revascularization procedures; stroke; clinical peripheral artery disease; current treatment with insulin or oral hypoglycemic drugs; fasting glucose $>126 \mathrm{mg} / \mathrm{dl}$, or casual glucose $>200 \mathrm{mg} / \mathrm{dl}$; more than $20 \mathrm{~g} /$ daily of alcohol intake; severe medical condition that may impair the person to participate in a nutritional intervention study; people following a special diet or involved in a program for weight loss, or who had experienced recent weight loss and inability to follow a diet for religious or other reasons. The assessment of alcohol intake was performed by means of a questionnaire [16] and a personal interview.

In this study, we present data obtained at baseline from 101 subjects (55 males and 46 females) enrolled consecutively in NUTRIATT study. Participants were fasted for $12 \mathrm{~h}$ prior to examination. Blood samples taken from the subjects by venous puncture were collected in tubes containing Ethylenediamine tetraacetic Acid (K-EDTA) anticoagulant.

For in vitro isolation of erythrocytes, blood samples with K-EDTA were quickly layered on a Ficoll-Paque solution and centrifuged at $400 \times g$ for $40 \mathrm{~min}$ at $20^{\circ} \mathrm{C}$. The lymphocytes and plasma were then removed and the erythrocytes were recovered from the bottom layer and washed with 4-volumes of phosphate-buffered saline. Isolated red blood cells were stored at $-80{ }^{\circ} \mathrm{C}$ until they were assayed. Moreover, aliquots of blood serum were taken from each subject and shipped to the central laboratory for routine analyses. All the analyses were performed within 3 months.

All subjects gave their informed consent to participate in the study.

\section{Fatty acids extraction, purification and preparation of fatty acid methyl esters}

We used the modified method of Moilanen [17], that is itself a modification of the method described by Folch [18]. Each sample of red blood cells (RBC) was thawed bringing to room temperature. Fatty acids were hydrolyzed from phospholipids of $\mathrm{RBC}$ membranes by adding $0.9 \mathrm{ml}$ of an acidified salt solution $\left(\mathrm{H}_{2} \mathrm{SO}_{4} 2 \cdot 10^{-4} \mathrm{M}\right.$, $\mathrm{NaCl} 0.1 \%$ ). Afterwards, were added $5.0 \mathrm{ml}$ of chloroform: methanol $(2: 1, v / v)$ (Sigma-Aldrich, Milan, Italy) and the samples were mixed thoroughly and centrifuged at $1000 \times g$ for $10 \mathrm{~min}$. The lower layer, containing fatty acids, was removed with care, replaced in a new tube and dried by a centrifugal evaporator (Bio-Rad, Milan, Italy). Preparation of fatty acid methyl esters (FAME) was carried out by adding $1 \mathrm{ml}$ of toluene and $1.5 \mathrm{ml}$ of 
$\mathrm{BF}_{3} . \mathrm{MeOH} 14 \%$ (Sigma-Aldrich, Milan, Italy) and incubating for $2 \mathrm{~h}$ at $80{ }^{\circ} \mathrm{C}$. To the samples were added $2.5 \mathrm{ml}$ of $5 \%$ aqueous sodium chloride solution, $1.5 \mathrm{ml}$ of toluene and then centrifuged at $470 \times \mathrm{g}$ for $10 \mathrm{~min}$. The upper layer, containing FAME, was collected and transferred into a vial and analyzed.

\section{Gas chromatography and fatty acids quantification}

Fatty acids quantification was performed by using a gas chromatography equipment with auto-sampler, a split/ split less injector, FID detector and a hydrogen gas generator (Thermo Fisher Scientific, Milan, Italy). Separation of FAME was carried out on a BPX 70 capillary column SGE Analytical Science, P/N SGE054623, $60 \mathrm{~m} \times 0.25 \mathrm{~mm}$ ID - BPX70 0.25 UM (SGE Europe Ltd., United Kingdom). Hydrogen was used as carrier gas, $3.0 \mathrm{ml} \mathrm{min}{ }^{-1}$, constant flow mode; the amount injected was $1 \mu \mathrm{l}$ in split less mode (split flow $50 \mathrm{ml} \mathrm{min}$ ${ }^{-1}$, split less time $1 \mathrm{~min}$ ). The temperature of the injector and the FID detector were $250{ }^{\circ} \mathrm{C}$. The initial temperature of the oven was $40{ }^{\circ} \mathrm{C}$, then it increased to $170{ }^{\circ} \mathrm{C}$ at $10{ }^{\circ} \mathrm{C} \mathrm{min}{ }^{-1}$ for $5 \mathrm{~min}$, then to $200{ }^{\circ} \mathrm{C}$ at $4{ }^{\circ} \mathrm{C}$ $\mathrm{min}^{-1}$ for another $5 \mathrm{~min}$ and finally the temperature increased to $240{ }^{\circ} \mathrm{C}$ at $10{ }^{\circ} \mathrm{C} \mathrm{min}{ }^{-1}$ and held for $5 \mathrm{~min}$.

Quantification of fatty acid methyl esters was performed using a mixture of standards (Supelco 37Component FAME Mix, Sigma-Aldrich, Milan, Italy).

\section{Statistical analysis}

All data were expressed as mean \pm SD. ANOVA and Tukey Multiple comparison test were performed to estimate differences among groups. A probabilistic type I error of $\leq 0.05$ was considered as statistically significant.

Multivariate regression analysis was performed to evaluate the role of confounding factors on final results. All analysis were performed by using Stata 14.2 statistical software.

\section{Results}

Table 1 shows clinical and biochemical characteristics of subjects at the baseline stratified for degree of NAFLD. We found 24 subjects with absentNAFLD (i.e. control group), 30 with moderate and 47 with severe NAFLD.

To probe the consistency and validity of our estimates we performed a post-hoc sample size estimation by taking into account our effect estimates. Type I $(\alpha)$ and II $(\beta)$ probabilistic errors varied between 0.05 and 0.01 and between 0.20 and 0.05 respectively, so the power of the study varied from 0.80 to 0.95 . Sample sizes obtained varied from $n=4(\alpha=0.05$, power 0.80$)$ to $n=30$ $(\alpha=0.01$, power 0.95$)$ and then, the number of samples resulted appropriate.

The values of serum azotemia, ferritin, triglycerides, cholesterol-HDL, glycemia, insulin and HOMA index were significantly higher in the subjects with NAFLD compared to control group. Moreover, stratifying for

Table 1 Clinical and biochemical variables in controls and patients with NAFLD

\begin{tabular}{|c|c|c|c|c|}
\hline & $\begin{array}{l}\text { Controls }(n=24) \\
\text { mean } \pm \text { SD }\end{array}$ & $\begin{array}{l}\text { Moderate NAFLD }(n=30) \\
\text { mean } \pm \text { SD }\end{array}$ & $\begin{array}{l}\text { Severe NAFLD }(n=47) \\
\text { mean } \pm \text { SD }\end{array}$ & $P$ value \\
\hline Age & $50.8 \pm 8.4$ & $50.5 \pm 10.6$ & $50.5 \pm 10.6$ & 0.4 \\
\hline $\mathrm{BMI}$ & $30.9 \pm 3.2$ & $30.7 \pm 2.9$ & $32.3 \pm 4.9$ & 0.02 Controls vs Severe \\
\hline Azotemia & $21.5 \pm 21.5$ & $36.4 \pm 10.2$ & $34.6 \pm 9.8$ & 0.001 Controls vs Moderate and Severe \\
\hline Ferritin & $114.7 \pm 148.6$ & $137.9 \pm 142.2$ & $149.4 \pm 178.9$ & 0.42 \\
\hline ALT & $28.9 \pm 20.4$ & $29.2 \pm 10.3$ & $40.7 \pm 23.0$ & 0.02 Controls vs Severe \\
\hline AST & $21.91 \pm 4.18$ & $23.53 \pm 4.91$ & $29.37 \pm 10.84$ & 0.01 Controls vs Severe \\
\hline GGT & $29.9 \pm 46.5$ & $23.5 \pm 12.1$ & $31.9 \pm 28.3$ & 0.8 \\
\hline $\begin{array}{l}\text { Total } \\
\text { cholesterol }\end{array}$ & $198.6 \pm 33.3$ & $210.6 \pm 33.9$ & $208.6 \pm 35.9$ & 0.28 \\
\hline $\begin{array}{l}\text { Cholesterol- } \\
\mathrm{HDL}\end{array}$ & $51.6 \pm 13.2$ & $48.1 \pm 13.7$ & $41.1 \pm 8.3$ & 0.001 Controls vs Severe \\
\hline Triglycerides & $100.7 \pm 46.5$ & $118.7 \pm 69.1$ & $151.2 \pm 89.0$ & 0.01 Controls vs Severe \\
\hline Glycemia & $87.4 \pm 12.2$ & $93.2 \pm 6.0$ & $98.8 \pm 15.1$ & 0.001 Controls vs Severe \\
\hline $\begin{array}{l}\text { Serum } \\
\text { Insulin }\end{array}$ & $7.18 \pm 3.03$ & $9.65 \pm 3.96$ & $13.2 \pm 4.8$ & $\begin{array}{l}0.04 \text { and } 0.001 \text { Controls vs Moderate and } \\
\text { Severe, respectively }\end{array}$ \\
\hline HOMA index & $1.59 \pm 0.72$ & $2.22 \pm 0.90$ & $3.16 \pm 1.27$ & $\begin{array}{l}0.04 \text { and } 0.001 \text { Controls vs Moderate and } \\
\text { Severe, respectively }\end{array}$ \\
\hline SFAs & $52.6 \pm 8.8$ & $52.3 \pm 9.6$ & $53.1 \pm 10.9$ & 0.84 \\
\hline MUFAs & $22.4 \pm 5.5$ & $22.6 \pm 6.2$ & $22.0 \pm 7.2$ & 0.8 \\
\hline PUFAs & $24.9 \pm 5.7$ & $25.0 \pm 4.6$ & $24.8 \pm 5.6$ & 0.9 \\
\hline
\end{tabular}


score of NAFLD, a significant trend from lower to higher degree of NAFLD for these parameters was also detected (Table 1).

Figure 1 shows a representative profile of fatty acids composition of erythrocytes membrane from a subject with severe NAFLD and a subject without liver injury.

A significant decrease of the erythrocyte membrane SI was observed in subjects with severe NAFLD compared to controls, $1.281 \pm 0.31$ vs $1.5 \pm 0.29$, (Fig. $2, p=0.01$, ANOVA and Tukey Multiple comparison test). Lowering of SI was essentially due to the increase of oleic acid content detected in these samples.

On the other hand, compared to controls, the subjects with severe NAFLD showed higher levels of SI $\mathrm{n}-7$, defined as palmitic to palmitoleic acid ratio (Fig. 3, $p<0.05$, ANOVA and Tukey Multiple comparison test). Moreover, the subjects with severe NAFLD reported enhanced levels of elongase activity, showing high levels of vaccenic acid (Fig. 1), a product derived from palmitoleic acid through the enzymatic activity of elongase 5 (Elovl5), (Fig. 4, $p<0.05$, ANOVA and Tukey Multiple comparison test).
No significant difference, among groups, was observed in fatty acids profile regarding total Saturated Fatty Acids (SFAs), Monounsaturated Fatty Acids (MUFAs) and PUFAs levels.

To evaluate the role of confounding factors on final results, we performed a multivariate regression analysis (Table 2). In the subjects with moderate and severe NAFLD, SI value was confirmed to be significantly lower respect to controls. This findings supports a role of SI as a biomarker of liver damage.

\section{Discussion}

The clinical importance of NAFLD is linked to evidence that it might evolve in steatohepatitis, liver cirrhosis and cancer [19]. In the effort to detect novel and noninvasive biomarkers for diagnosis of NAFLD, this study demonstrates a relationship between alterations of circulating cell membrane lipidomic profile and degree of liver injury. Lower levels of SI in red blood cell membranes, detected in the patients with severe NAFLD, suggest an impairment of circulating cell membrane

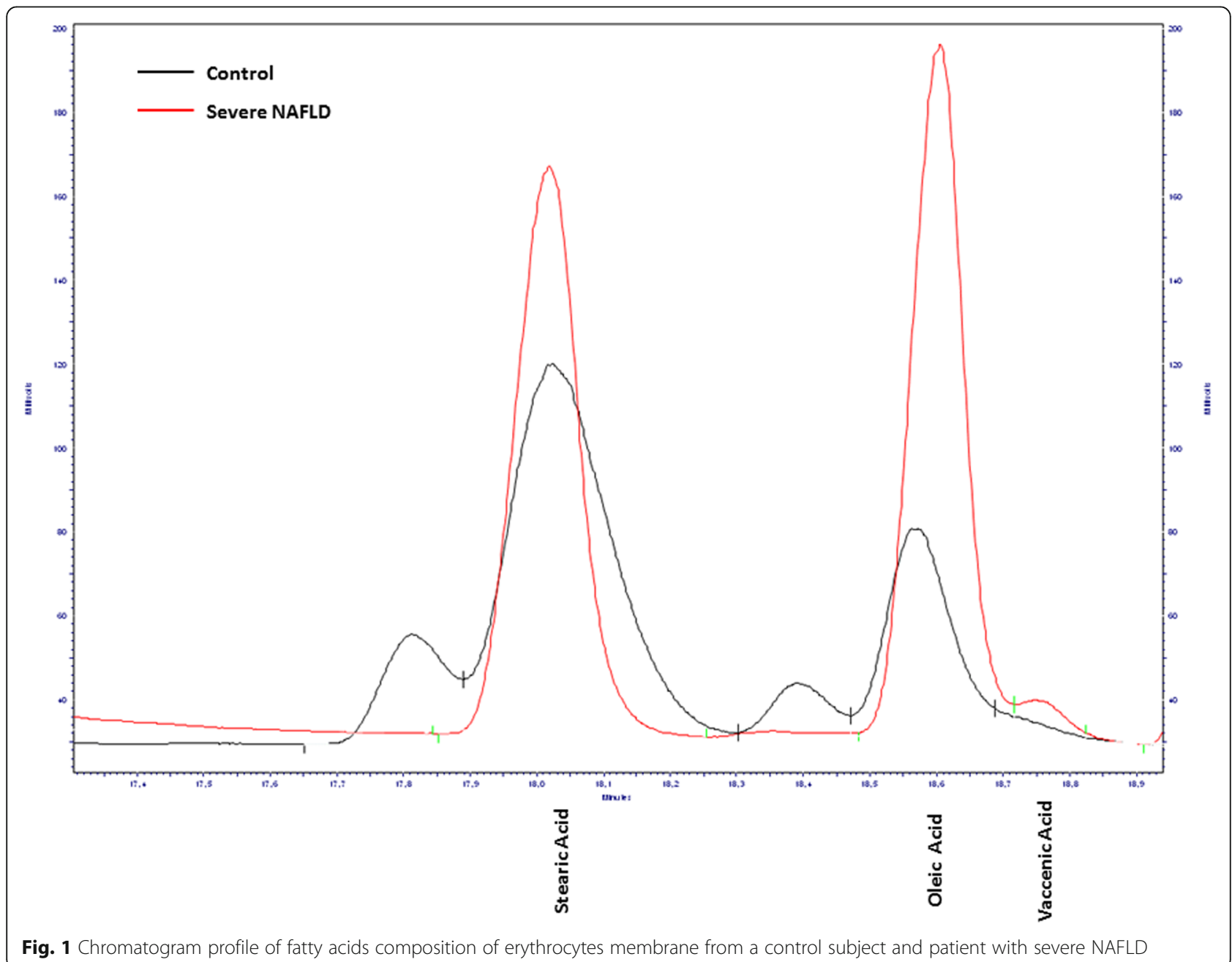




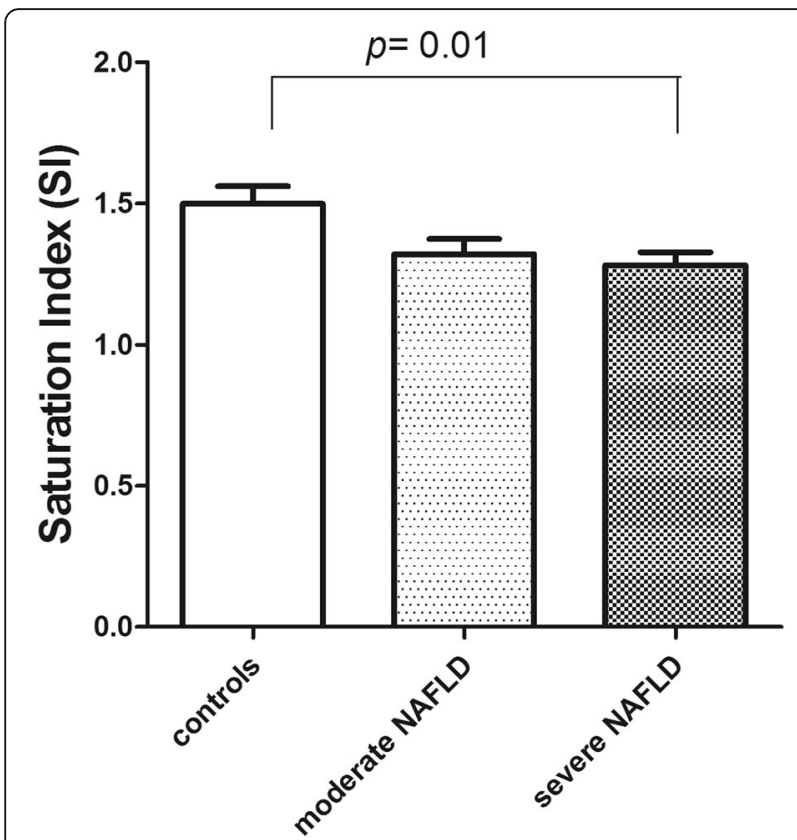

Fig. 2 Saturation index (SI) levels (stearic acid/oleic acid ratio) in erythrocytes membranes from controls and patients with moderate and severe NAFLD. Data are expressed as the mean \pm SD. $P<0.05$, one-way analysis of variance and Tukey's multiple comparison test

structure that can reflect modifications that take place in the liver.

It is widely known that in the pathophysiology of NAFLD, an elevated content of lipids in hepatic tissue, is a major cause of liver damage, affecting cell membrane structure [20].

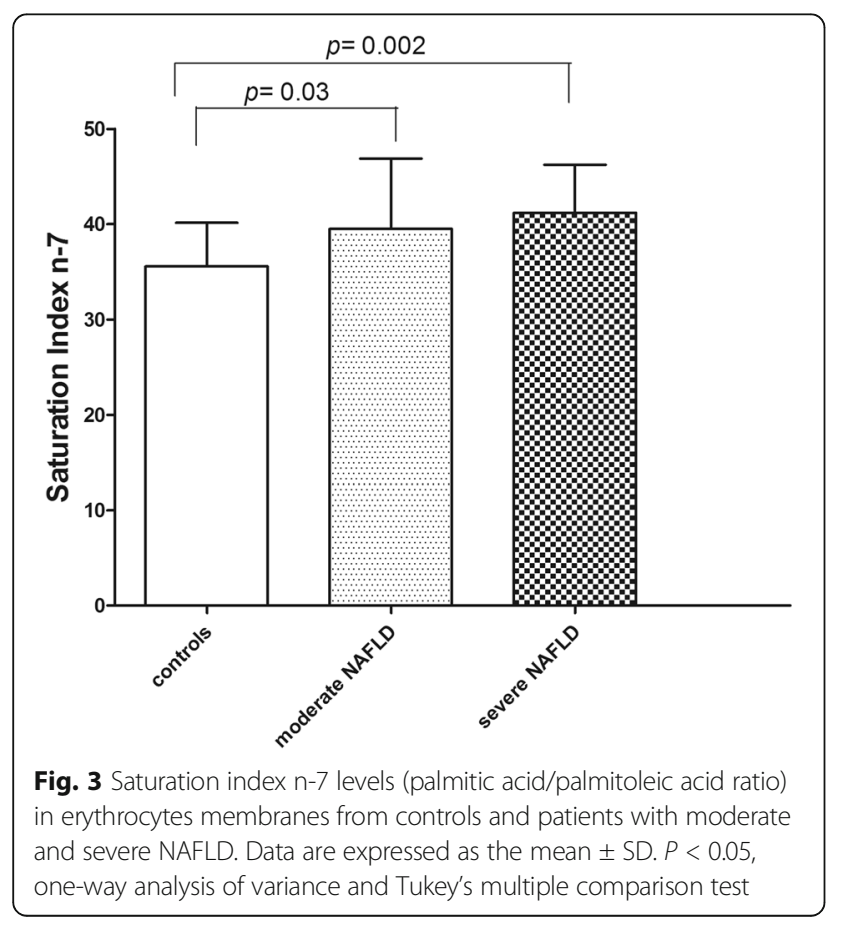

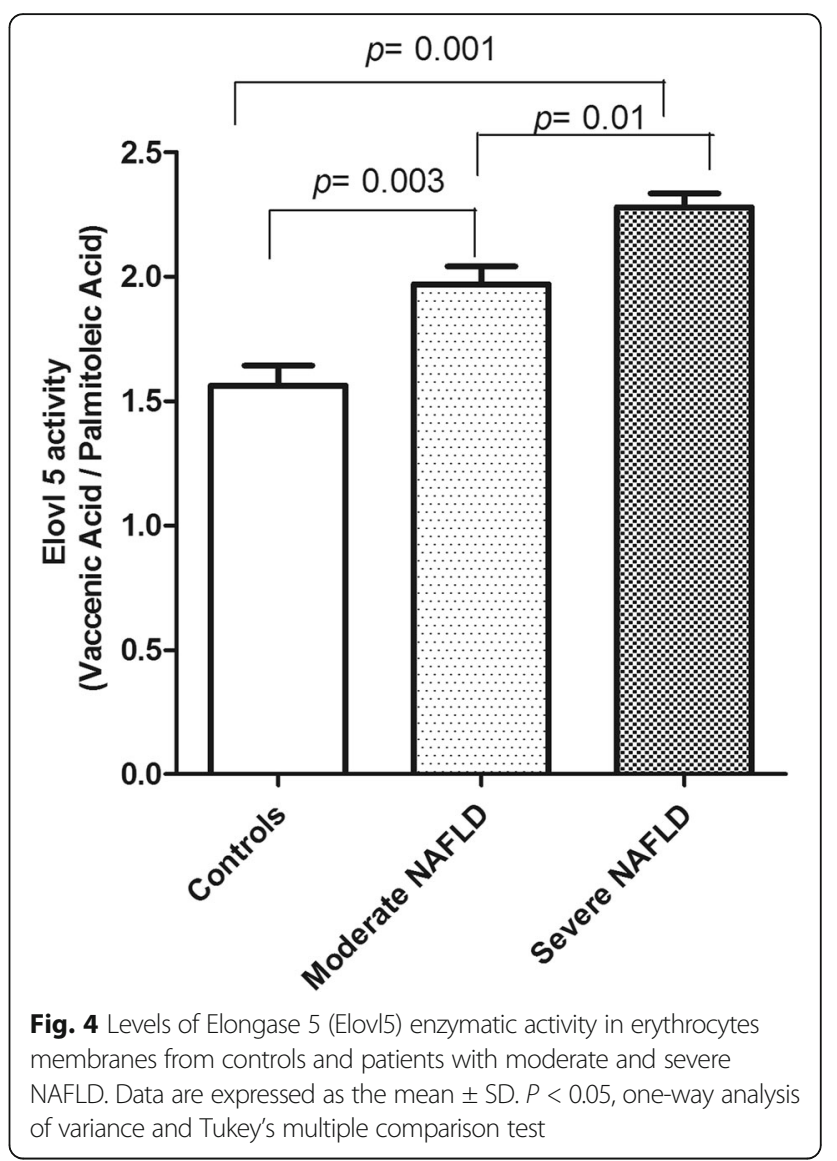

In this context, we found the SI in red blood cells to be inversely associated with degree of liver damage. This finding, was also confirmed by multivariate regression analysis, supporting a role of SI as a biomarker of liver injury.

Elevated levels of oleic acid in erythrocytes membrane and consequently low levels of SI have been demonstrated in different pathological conditions [8, 21]. Low levels of SI have been associated with an increased cancer risk [3, 8], suggesting that the regulation of membrane fluidity is essential for the metabolic functionality of cells. The reduction of membrane rigidity seems to lead to increased cell metabolism and to higher cell proliferation activity, both features of neoplastic cells.

In this study, we showed that the ratio of saturated to unsaturated fatty acids can be a marker of liver damage and indirectly that the maintenance of normal oleic acid content might preserve the fluidity of membranes, a key feature of cell homeostasis.

Several studies have demonstrated that in the pathogenesis of NAFLD, an altered regulation of desaturation and elongation processes of fatty acids are present. High levels palmitic to palmitoleic acid ratio and lower levels of oleic acid to stearic acid ratio, observed in patients with NAFLD, are probably 
Table 2 Multivariate Regression Analysis: Effect of NAFLD score on red blood cell lipid profile

\begin{tabular}{|c|c|c|c|c|c|c|}
\hline & $\begin{array}{l}\text { SFAs } \\
(95 \% \text { C.I.) }\end{array}$ & $\begin{array}{l}\text { MUFAs } \\
\text { (95\% C.I.) }\end{array}$ & $\begin{array}{l}\text { PUFAs } \\
(95 \% \text { C.I.) }\end{array}$ & $\begin{array}{l}\text { SI } \\
(95 \% \text { C.I.) }\end{array}$ & $\begin{array}{l}\text { SI n-7 } \\
(95 \% \text { C.I.) }\end{array}$ & $\begin{array}{l}\text { Elovl5 } \\
\text { (95\% C.I.) }\end{array}$ \\
\hline \multirow[t]{2}{*}{ Moderate NAFLD } & -2.07 & 0.25 & 1.82 & $-0.65^{*}$ & 16.81 & 0.64 \\
\hline & $(-8.51,4.37)$ & $(-3.92,4.41)$ & $(-1.66,5.30)$ & $(-1.19,-0.11)$ & $(-19.49,53.11)$ & $(-5.66,6.94)$ \\
\hline \multirow[t]{2}{*}{ Severe NAFLD } & -1.54 & -0.59 & 2.089 & $-0.54^{*}$ & 25.56 & -0.20 \\
\hline & $(-7.86,4.85)$ & $(-4.71,3.52)$ & $(-1.34,5.52)$ & $(-1.08,-0.01)$ & $(-10.26,61.38)$ & $(-6.41,6.02)$ \\
\hline \multirow[t]{2}{*}{ Age (years) } & 0.23 & -0.17 & -0.065 & 0.01 & -0.76 & 0.08 \\
\hline & $(-0.06,0.52)$ & $(-0.36,0.02)$ & $(-0.22,0.09)$ & $(-0.02,0.03)$ & $(-2.41,0.90)$ & $(-0.02,0.37)$ \\
\hline \multirow[t]{2}{*}{ Gender (Female) } & 15.34 & -8.20 & -7.110 & -0.25 & -0.40 & 3.83 \\
\hline & $(-6.95,37.64)$ & $(-22.64,6.22)$ & $(-19.15,4.93)$ & $(-2.13,1.62)$ & $(-126.03,125.24)$ & $(-17.98,25.63)$ \\
\hline
\end{tabular}

$(95 \%$ C.I. $) * 0<0.05 ; \wedge$ Adjusted for Age, Gender and biochemical markers

due to an increased chain elongation and to an altered control of desaturase signaling. A key role in these enzymatic processes is played by stearoylcoenzyme A desa turase 1, an important enzyme of triglycerides biosynthesis, specific lipid class accumulated in livers of subjects with NAFLD [22].

Low content of palmitoleic acid, detected in red blood cells membranes of the subjects with severe NAFLD, was justified by high levels of elongase 5 (Elov15) activity. Elevated activity of Elovl5 enzyme leads to a higher transformation rate of palmitoleic acid in vaccenic acid. Regarding C18:1 n-7, likely cis- vaccenic acid, a recent study suggested a role for this fatty acid in the development of chronic kidney disease [23]. Moreover, circulating concentrations of cis-vaccenic acid have been demonstrated to be associated with an increased risk of coronary heart disease and cardiac arrest $[24,25]$.

Consistently with our data, being NAFLD associated with cardiovascular diseases [26], high levels of cisvaccenic acid, correlated with higher degree of liver damage detected in this study, confirm the role for specific fatty acids species in the onset of metabolic pathologies.

\section{Conclusions}

We conclude that the lipidomic approach is important in the diagnosis and the staging of NAFLD. Our data, overall, suggest that SI could be used as a biomarker of liver injury in order to assess therapeutic intervention to restore membrane fatty acids profile. Changes in the dynamics of the fatty acid metabolic processes through diet and life style can be beneficial for the patients with this metabolic disease.

\section{Acknowledgments}

This work was supported by "PO Puglia FESR 2007-2013, Asse I, Linea 1.2. Accordo di Programma Quadro in materia di Ricerca Scientifica. Intervento "Reti di Laboratori Pubblici di Ricerca". Progetto L.A.I.F.F. - Rete Di Laboratori Per L'innovazione Nel Campo Degli Alimenti Funzionali (codice n. 47)".
Available of data and materials

The dataset generated and/or analyzed during the current study are available from the corresponding author on reasonable request.

\section{Authors' contributions}

Notarnicola M and Osella AR have equally contributed to this work; Osella AR conceived and designed the study; Notarnicola M analyzed the data and wrote the paper; Franco I and Mirizzi A enrolled the subjects; Tutino $V$ and De Leonardis G carried out the gas chromatography analysis; De Nunzio V and Intini $V$ performed fatty acids extraction; Cozzolongo R and Giannuzzi V performed elastography by FibroScan; Bonfiglio $\mathrm{C}$ and Abbrescia DI analyzed the data; Caruso MG interpreted the data and reviewed the manuscript. All authors read and approved the final manuscript.

\section{Ethics approval and consent to participate}

The study was approved by the Ethics Committee of our Institute (Project identification code $n^{\circ}$ 6/CE IRCCS "De Bellis").

\section{Consent for publication}

The authors have agreed to the submission of the final manuscript.

\section{Competing interests}

All authors declare that they have no competing interests.

\section{Publisher's Note}

Springer Nature remains neutral with regard to jurisdictional claims in published maps and institutional affiliations.

Received: 6 July 2017 Accepted: 15 August 2017

Published online: 23 August 2017

\section{References}

1. Habib NA, Wood CB, Apostolov K, Barker W, Hershman MJ, Aslam M, Heinemann D, Fermor B, Williamson RCN, Jenkins WE, Masters JRW, Embleton MJ. Stearic acid and carcinogenesis. Br J Cancer. 1987:56:455-8.

2. Cooper RA. Abnormalities of cell-membrane fluidity in the pathogenesis of disease. N Engl J Med. 1977;297:371-7.

3. Wood CB, Habib NA, Thompson A, Bradpiece H, Smadja C, Hershman M, Barker W, Apostolov K. Increase of oleic acid in erythrocytes associated with malignancies. Br Med J. 1985;291:163-5.

4. Persad RA, Gillatt DA, Heinemann D, Habib NA, Smith PJ. Erythrocyte stearic to oleic acid ratio in prostatic carcinoma. Br JUrol. 1990;65:268-70.

5. Puri P, Baillie RA, Wiest MM, Mirshahi F, Choudhry J, Cheung O, Sargeant C, Contos JC, Sanyal AJ. A lipidomic analysis of non-alcoholic fatty liver disease. Hepathology. 2007:46:1081-90.

6. Serviddio G, Bellanti F, Villani R, Tamborra R, Zerbinati C, Blonda M, Ciacciarelli M, Poli G, Vendemiale G, Iuliano L. Effects of dietary fatty acids and cholesterol excess on liver injury: a lipidomic approach. RedBiol. 2016;9:296-305.

7. Pala V, Krogh V, Muti $P$, Chajès V, Riboli E, Micheli A, Saadatian M, Sieri S, Berrino F. Erythrocyte membrane fatty acids and subsequent breast cancer: a prospective Italian study. J Natl Cancer Inst. 2001;93:1088-95. 
8. Pandey M, Sharma LB, Singh S, Shukla VK. Erythrocyte membrane fatty acid profile and saturation index in gallbladder carcinogenesis: a case-control study. World JSurgOncol. 2003;1:5.

9. Coviello G, Tutino V, Notarnicola M, Caruso MG. Erythrocyte membrane fatty acids profile in colorectal cancer patients: a preliminary study. Anticancer Res. 2014;34:4775-9.

10. Apostolov K, Barker W, Catovsky D, Goldman J, Matutes E. Reduction in stearic to oleic in leukaemic cells: a possible chemical marker of malignancy. Blutalkohol. 1985;50:349-54.

11. Wood CB, Habib NA, Apostolov K, Thompson A, Smadja C, Hershman M, Baker W. Reduction in the stearic to oleic acid ratio in circulating red blood cells: a possible tumor marker in solid human neoplasm. Eur J Surg Oncol. 1985:11:167-9.

12. Chajes V, Hulten K, Van Kappel AL, Winkvist A, Kaaks R, Hallmans G, Lenner P, Riboli E. Fatty acid composition in serum phospholipids and risk of breast cancer: an incident case-control study in Sweden. Int J Cancer. 1999;83:585-90.

13. Almeda-Valdes P, Altamirano-Barrera A, Mendez-Sanchez N. Insights in non-alcoholic fatty liver disease pathophysiology with lipidomic analyses. Annals of Hepatol. 2015;14:567-9.

14. Berzigotti A. Non-invasive assessment of non-alcoholic fatty liver disease: ultrasound and transient elastography. Rev Rec Clin Trials. 2014;9:170-7.

15. Berzigotti A. Getting closer to a point-of-care diagnostic assessment in patients with chronic liver disease: controlled attenuation parameter for steatosis. JHepatol. 2014;60:910-2.

16. Skinner HA, Sheu WJ. Reliability of alcohol use indices. The lifetime drinking history and the MAST. J Stud Alcohol. 1982:43:1157-70.

17. Moilanen T, Nikkari T. The effect of storage on the fatty acid composition of human serum. Clin Chim Acta. 1981;114:111-6.

18. Folch J, Lees M, Sloane Stanley GH. A simple method for the isolation and purification of total lipids from animal tissues. J BiolChem. 1957;226:497-509.

19. Caldwell SH, Crespo CM. The spectrum expanded: cryptogenic cirrhosis and the natural history of non-alcoholic fatty liver disease. JHepatol. 2004;40:578-84.

20. Matsuzawa N, Takamura T, Kurita S, Misu H, Ota T, Ando H, Yokoyama M, Honda M, Zen Y, Nakanuma Y, Miyamoto K, Kaneko S. Lipid-induced oxidative stress causes steatohepatitis in mice fed with an atherogenic diet. Hepatology. 2007:46:1392-403.

21. Kelly SB, Miller J, Wood CB, Williamson RCN, Habib NA. Erythrocyte stearic acid desaturation in patients with colorectal carcinoma. Dis Colon Rectum. 1990:33:1026-30.

22. Yee JK, Mao CS, Hummel HS, Lim S, Sugano S, Rehan VK, Xiao G, Lee WNP. Compartmentalization of stearoyl-coenzyme a desaturase 1 activity in HepG2 cells. J Lipid Res. 2008;49:2124-34.

23. Block R, Kakinami L, Liebman S, Shearer GC, Kramer H, Tasi M. Cis-vaccenic acid and the Framingham risk score predict chronic kidney disease: the multi-ethnic study of atherosclerosis (MESA). Prostagl Leuk Essen Fatty Acid. 2012;86:175-82.

24. Djoussè L, Matthan NR, Lichtenstein AH, Gaziano JM. Red blood cell membrane concentration of cis-palmitoleic and cis-vaccenic acids and risk of coronary heart disease. Am J Cardiol. 2012;110:539-44.

25. Wu JHY, Lemaite RN, Imamura F, King IB, Song $X$, Spiegelman D, Siscovick DS, Mozaffarian D. Fatty acids in de novo lipogenesis pathway and risk of coronary heart disease: the cardiovascular health study. Am J Clin Nutr. 2011;94:431-8.

26. Targher G, Byrne CD, Lonardo A, Zoppini G, Barbui C. Nonalcoholic fatty liver disease and risk of incident cardiovascular disease: a meta-analysis of observational studies. J Hepatol. 2016:65:589-600.

\section{Submit your next manuscript to BioMed Central and we will help you at every step:}

- We accept pre-submission inquiries

- Our selector tool helps you to find the most relevant journal

- We provide round the clock customer support

- Convenient online submission

- Thorough peer review

- Inclusion in PubMed and all major indexing services

- Maximum visibility for your research

Submit your manuscript at www.biomedcentral.com/submit

) Biomed Central 